\title{
Mental health outcomes after major trauma in Ontario: a population-based analysis
}

\author{
Christopher C.D. Evans MD MSc, Yvonne DeWit MSc, Dallas Seitz MD PhD, Stephanie Mason MD PhD, \\ Avery Nathens MD PhD, Stephen Hall MD
}

Cite as: CMAJ 2018 November 12;190:E1319-27. doi: 10.1503/cmaj.180368

Visual abstract available at www.cmaj.ca/lookup/suppl/doi:10.1503/cmaj.180368/-/DC2

\begin{abstract}
BACKGROUND: Major injury continues to be a common source of morbidity and mortality; improving the functional recovery of survivors of major trauma requires a better understanding of the mental health outcomes that may occur in this population. We assessed the association between major trauma and the development of a new mental health diagnosis or death by suicide.
\end{abstract}

METHODS: We completed a populationbased, self-controlled, longitudinal cohort analysis using linked administrative data on patients treated for major trauma in Ontario between 2005 and 2010. All survivors were included and composite rates of mental health diagnoses during inpatient admissions were compared between the 5 years after injury and the 5 years before injury, using Poisson regression with generalized estimating equations. The incidence of suicide was calculated for the 5 years after injury. Risk factors for suicide were calculated using Cox proportional hazard regression analyses.

RESULTS: The analysis included 19338 patients, predominantly men $(70.7 \%)$ from urban areas $(82.6 \%)$, with unintentional (89\%), blunt injuries (93.4\%). Overall, trauma was associated with a $40 \%$ increase in the postinjury rate of mental health diagnoses (incidence rate ratio
[IRR] 1.4, 95\% [confidence interval] $\mathrm{Cl} 1.1$ to 1.8). The suicide rate was 70 per 100000 patients per year, substantially higher than the population average. Risk factors for completing suicide were prior inpatient diagnosis of mood disorder (hazard ratio [HR] 4.3, 95\% $\mathrm{Cl} 2.1$ to 8.8 ) and selfinflicted injury (HR 7.8, 95\% $\mathrm{Cl} 3.9$ to 15.4 ).

INTERPRETATION: Survivors of major trauma are at a heightened risk of developing mental health conditions or death by suicide in the years after their injury. Patients with pre-existing mental health disorders or who are recovering from a self-inflicted injury are at particularly high risk. njuries have been described as the "neglected disease" of modern times. ${ }^{1}$ Major trauma is the leading cause of death in the first 3 decades of life and the most common cause of major disability thereafter. ${ }^{2}$ Poor mental health outcomes, such as the development of depression, posttraumatic stress disorder, chronic pain and suicidality, have become increasingly recognized factors in patients in poor recovery from major injury. ${ }^{1-3}$

There is surprisingly little literature on the association between major injury and subsequent mental health outcomes. Although nearly $87 \%$ of patients with major trauma survive to discharge, ${ }^{4}$ most trauma registries do not track patients after discharge, limiting our ability to understand the trajectory of patients' recovery beyond the acute phase of injury.

Emerging evidence shows that survivors of trauma are at heightened risks of developing major mental health disorders. ${ }^{1,2,5-9}$ Some patients progress to attempt or die by suicide. ${ }^{2,7}$ For instance, 1 study followed patients admitted to US level 1 trauma centres and found symptoms of depression in $20 \%$ and posttraumatic stress disorder in $6 \%$ of patients. ${ }^{10}$ Similarly, data from Australia show that $31 \%$ of survivors of trauma have a diagnosed psychiatric disorder by 12 months postinjury, including depression (9\%) and posttraumatic stress disorder (6\%). ${ }^{1}$ Canadian data also suggest that more moderate, isolated injuries, such as concussions, may be associated with suicide. ${ }^{11}$ More knowledge about the association between injury and mental health outcomes is needed to optimize the care of survivors of trauma.

Our study builds on previous work by using large, linked, population-level health databases; a robust self-matched, before-and-after cohort design to control for confounding; and prolonged pre- and postinjury study periods. Our primary objective was to determine whether major injury is a risk factor for developing a new mental health diagnosis or death by suicide. Our secondary objective was to identify risk factors for death by suicide among this patient population. 


\section{Methods}

\section{Study design}

We conducted a retrospective, population-based, longitudinal cohort study of all patients who survived major traumatic injury in Ontario, Canada, from 2005 to 2010. We used an exposurecrossover design in which patients acted as their own controls, ${ }^{12}$ thus minimizing confounding related to stable characteristics like genetics and personality. The incidence of mental health diagnoses in the 5 years preceding injury (the exposure) was compared with the incidence of mental health diagnoses in the 5 years after injury. We also determined incidence of suicide in the 5 years after injury in the cohort.

\section{Setting}

Ontario is Canada's most populous province, with more than 13 million inhabitants,,$^{13}$ who are covered by a universal health insurance program (Ontario Health Insurance Program [OHIP]) that pays for primary, emergency and in-hospital services. OHIPrelated electronic health data are held by ICES, an independent, nonprofit research organization funded by the Ontario Ministry of Health and Long-Term Care. The ICES electronic data holdings include all OHIP-insured health care-related events for the complete population of Ontario enrolled in OHIP, linked to other data sources using an anonymous, unique identifier for each patient. Other data sources include databases from the Canadian Health Institute for Health Information (CIHI): the Discharge Abstract Database and Ontario Mental Health Reporting System, which capture inpatient visits, and the National Ambulatory Care Reporting System for visits to emergency departments. These data contain visit characteristics including diagnostic and therapeutic information.

All lead trauma hospitals in Ontario submit data on patients they treat to the Ontario Trauma Registry. Major traumatic injuries are defined as those with an injury severity score $\geq 12$ and an appropriate external cause of injury code from the International Classification of Disease 9th (ICD9) or 10th revision Canada (ICD10-CA) (Appendices 1 and 2, available at www.cmaj.ca/ lookup/suppl/doi:10.1503/cmaj.180368/-/DC1). Ontario has 11 designated lead trauma hospitals, including 2 pediatricspecific centres; when possible, patients are transported directly from the scene of injury to these designated trauma centres according to pre-hospital triage guidelines. Other patients are secondarily transferred to the lead trauma hospitals after they are assessed and stabilized at another acute care hospital.

We linked Ontario Trauma Registry records to their corresponding records in the National Ambulatory Care Reporting System or the Discharge Abstract Database for additional information about the episode of care for the injury. We used OHIP billing data to determine whether patients had trauma surgery during their care.

We linked these data sets using unique encoded identifiers and analyzed them at ICES. By linking the different administrative data sets, we were able to re-create the clinical trajectory for each anonymous patient so as to better understand the impact of major traumatic injury on subsequent mental health.

\section{Participants}

We included patients with a major traumatic injury from the Ontario Trauma Registry who were discharged between Apr. 1, 2005, and Dec. 31, 2010. As per the flow chart in Figure 1, we excluded individuals if they met any of the following criteria: did not reside in Ontario; died during admission; had more than 1 entry in the Ontario Trauma Registry between 2005 and 2015; had a previous traumatic injury before 2005; for whom emergency department or inpatient hospital records matching the injury could not be identified from $\mathrm{ClHI}$ data (using National Ambulatory Care Reporting System and Discharge Abstract Database data); and were not eligible for OHIP at any time before the injury.

Patient variables included age, sex and comorbidities. We used the Elixhauser comorbidity adjustment ${ }^{14-16}$ to measure comorbidity burden. As a measure of socioeconomic status, we used postal codes to determine neighbourhood income quintile and rurality (based on the Rurality Index for Ontario ${ }^{17}$ ) for the year in which the trauma occurred. Injury-related variables included type and mechanism of injury, incident location, whether the injury was intentional, and measures of severity such as the injury severity score, treatments received and postacute care disposition.

\section{Primary outcome}

The primary outcome was the composite rate of mental health diagnoses during inpatient admissions in the 5 years after injury, compared with the 5 years before the injury. These inpatient admissions included admission to inpatient psychiatric units and

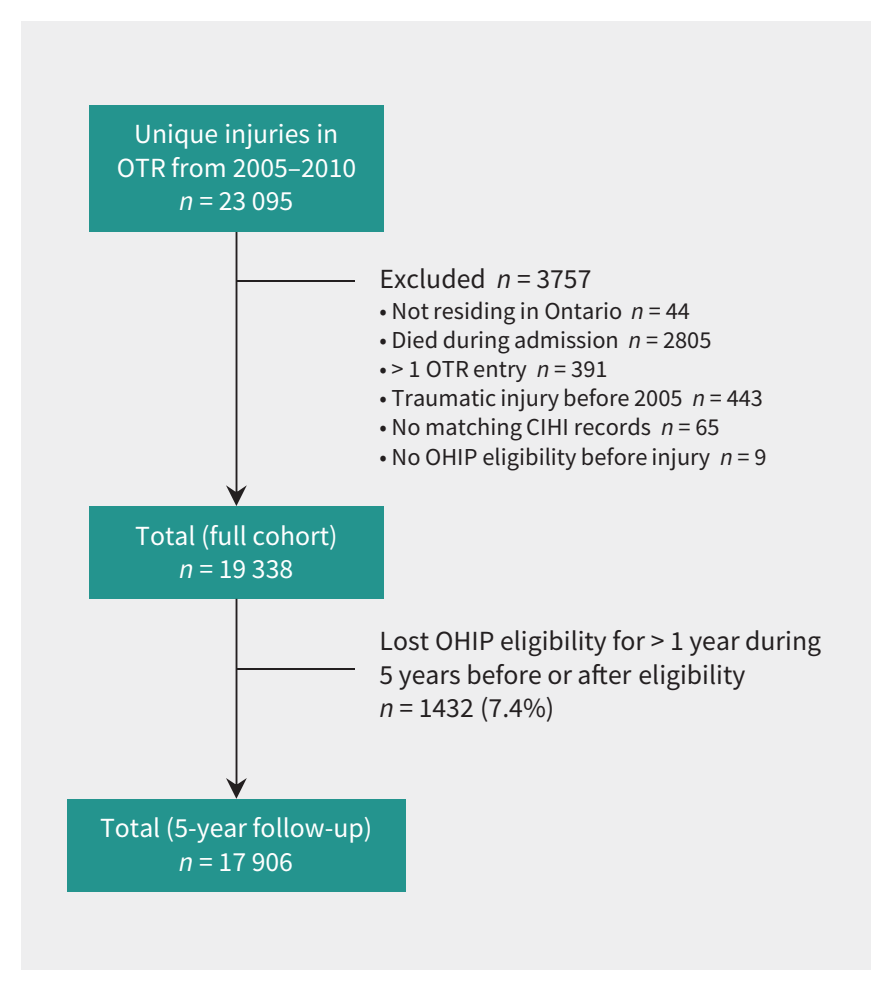

Figure 1: Data set creation flowchart. Note: $\mathrm{ClHI}=$ Canadian Institute of Health Information, OHIP = Ontario Health Insurance Plan, OTR = Ontario Trauma Registry. 
admissions with confirmed mental health diagnoses. Typically, confirmed diagnoses are based on psychiatric or psychological assessment or records of previous assessment. We did not include suspected diagnoses. Diagnoses were based on ICD9, ICD10-CA and Diagnostic and Statistical Manual of Mental Disorders 4th edition (DSM-IV) diagnostic codes for mood, substance, self-harm and anxiety disorders (Appendix 3, available at www. cmaj.ca/lookup/suppl/doi:10.1503/cmaj.180368/-/DC1). We focused on inpatient visits rather than outpatient visits, as we felt the former would be a more reliable source of diagnostic information, although also representative of more serious mental health problems. We also grouped mental health diagnoses to investigate the association between traumatic injury and different types of mental health conditions.

\section{Secondary outcome}

The secondary outcome for this study was the rate of deaths by suicide among individuals who have had traumatic injuries, using death data from the Office of the Registrar General in Ontario. ICD10-CA codes X60-X84 and Y10-Y34 were used to determine suicide from 2005 to 2012, and "manner of death = suicide" was used to determine suicide in 2013 ("manner of death" is a new field that began to be used in 2013), as has been done in previous ICES studies. ${ }^{11}$

\section{Statistical analysis}

We performed cross-tabulations and descriptive statistics for the baseline demographics and injury characteristics. We used Poisson regression with generalized estimating equations to estimate pre-injury and postinjury rates of inpatient visits for mental health conditions. Incidence rate ratios (IRRs) were calculated comparing postinjury to pre-injury rates. Univariate (unadjusted) and multivariate (adjusted) models were computed investigating the effects of gender, age group, neighbourhood income quintile, home location (rural or small town v. urban), nature of injury and requirement for trauma surgery on pre- and postinjury rates of mental health conditions. The suicide rate was calculated by counting the number of deaths by suicide divided by the total amount of person-years of follow-up time on the study.

We used Cox proportional hazard models to investigate factors associated with suicide. In addition to the characteristics included in the above analyses, we hypothesized the following variables a priori to be predictors of suicide: previous inpatient visits for mental health conditions, injury severity, number of operations and discharge to a nonhome setting. Each potential predictor was included first in a simple univariate model, and then included for model building of the multivariate model. Backward selection at $\alpha=0.10$ was used to determine which variables remained in the multivariate model.

\section{Ethics approval}

The study was approved by the Health Sciences and Affiliated Teaching Hospitals Research Ethics Board of Queens University, and by the Institutional Review Board at Sunnybrook Health Sciences Centre, Toronto, Canada.
Table 1: Baseline characteristics of the study population $(n=19338)$

\section{Characteristic}

No. of patients (\%)

Sex

Female

$5675(29.4)$

Male

$13663(70.7)$

Age group, yr

$<12$

$1013(5.2)$

13-17

$1293(6.7)$

18-29

$3743(19.4)$

30-49

$4625(23.9)$

$50-69$

4613 (23.9)

$70+$

4051 (21)

Neighbourhood income quintile

Lowest

$4313(22.3)$

Next to lowest

$4008(20.7)$

Middle

$3710(19.2)$

Next to highest

3786 (19.6)

Highest

$3381(17.5)$

Missing

$140(0.7)$

Rurality

Rural or small town

$3357(17.4)$

Urban

$15981(82.6)$

Total score of Elixhauser Comorbidity Index*

0

1

$14824(76.7)$

$2274(11.8)$

$2+$

2240 (11.6)

Comorbid conditions ${ }^{*}$

Cardiovascular disorders NOS

$1120(5.8)$

Hypertension

1081 (5.6)

Neurological disorders

$554(2.9)$

Chronic pulmonary disease

780 (4)

Diabetes

$1005(5.2)$

Hypothyroidism

$64(0.3)$

Renal failure

$243(1.3)$

Liver disease

$167(0.9)$

Peptic ulcer disease, excluding bleeding

$44(0.2)$

AIDS or HIV

$16(0.1)$

Cancer

$308(1.6)$

Rheumatoid arthritis or collagen vascular diseases

$63(0.3)$

Coagulopathy

$150(0.8)$

Obesity

$49(0.3)$

Weight loss

$102(0.5)$

Fluid and electrolyte disorders

$593(3.1)$

Anemia

$109(0.6)$

Inpatient admission in 5 years before injury

Any mental health condition

$1386(7.2)$

Anxiety and other neurotic disorders

$339(1.8)$

Mood disorders

$699(3.6)$

Substance abuse and related disorders

$821(4.3)$

Self-harm behaviours

$97(0.5)$ 
Table 2 (part 1 of 2): Injury-related characteristics of the study population ( $n=19338$ )

\section{Characteristic}

Year of injury $\dagger$

2005 or earlier

2006

2007

2008

2009

2010

Primary injury type

Missing

Blunt

Penetrating

Burns

Nature of injury or external cause of injury, code

Land transport incidents

Water transport incidents

Air and space transport incidents

Unintentional falls

Mechanical forces

Unintentional drowning, submersion or other unintentional threats to breathing

Exposure to electric current, radiation and extreme ambient air temperature and pressure

Exposure to smoke, fire and flames

Contact with heat and hot substances

Exposure to forces of nature

Intentional self-harm, excluding poisoning

Assault, excluding poisoning

Legal intervention and operations of war

Other $\ddagger$

Intentional injury

Missing

Unintentional

Self-inflicted

Homicide or assault

Place of injury

Missing

Home

Residential institution

School or other institution or public area

Sports or athletics area

Street or highway

Trade or service area

Industrial or construction area

Farm

Other specified place of occurrence

Unspecified place of occurrence
No. of patients (\%)*

2570 (13.3)

$3272(16.9)$

3496 (18.1)

3285 (17)

3416 (17.7)

$3290(17)$

$1(0)$

$18064(93.4)$

950 (4.9)

$323(1.7)$

$8911(46.1)$

$56(0.3)$

$33(0.2)$

6837 (35.4)

$996(5.2)$

$17(0.1)$

$15(0.1)$

$253(1.3)$

$42(0.2)$

$10(0.1)$

$322(1.7)$

$1611(8.3)$

$28(0.1)$

$207(1.1)$

$154(0.8)$

17202 (89)

$439(2.3)$

$1543(8)$

$105(0.5)$

4841 (25)

284 (1.5)

$426(2.2)$

409 (2.1)

8569 (44.3)

476 (2.5)

$542(2.8)$

$215(1.1)$

1148 (5.9)

$2323(12)$

\section{Results}

The study cohort consisted of 19338 patients identified in the Ontario Trauma Registry who did not meet any exclusion criteria (Figure 1). Of these patients, 1432 (7.4\%) lost OHIP eligibility for at least 1 year during the 5-year follow-up period, and were therefore excluded. The baseline characteristics of the full cohort used for analysis (Table 1) and those with complete follow-up for 5 years were very similar (Supplementary Table 1 [Appendix 4, available at www.cmaj.ca/lookup/suppl/ doi:10.1503/cmaj.180368/-/DC1]). The population was predominantly male (70.7\%), older than 18 years and had sustained traumatic injuries in urban regions of the province (82.6\%).

Examination of the injury characteristics of the study population (Table 2) showed significant predominance of blunt trauma (93.4\%), mainly owing to land transport accidents $(46.1 \%)$ and falls (35.4\%). Most injuries (89\%) were unintentional, and occurred either on streets or highways (44.3\%), or at home (25\%). The median injury severity score was 21 . About one-quarter (27.9\%) of patients received trauma surgery and $47.5 \%$ of patients were discharged home. Injury characteristics were very similar between the full cohort and the cohort with complete follow-up (Supplementary Table 2 [Appendix 5, available at www.cmaj.ca/lookup/ suppl/doi:10.1503/cmaj.180368/-/DC1]).

Composite rates of inpatient mental health diagnoses in the 5 years before and the 5 years after admission for major trauma are shown in Table 3, and adjusted rate ratios comparing pre- and posttrauma rates are displayed in Figure 2 . Overall, major trauma was associated with a $40 \%$ increased rate of hospital admission for 1 or more mental health diagnoses (IRR $1.4,95 \%$ confidence interval $[\mathrm{Cl}] 1.11$ to 1.18). The most common mental health diagnoses were alcohol abuse, other drug abuse disorders and major depressive disorders (Table 4). Factors associated with an increased rate of admission for a mental health diagnosis included male gender, extremes of socioeconomic status, living in rural dwellings, having unintentional injuries, and requiring operative intervention (Figure 2). Although a test for 
Table 2 (part 2 of 2): Injury-related characteristics of the study population ( $n=19338)$

\section{Characteristic}

No. of patients (\%)

Injury severity score

9-15

$1917(10.1)$

$16-24$

$9076(47.7)$

$25-40$

$41-49$

$50-75$

Injury severity score on arrival to trauma hospital, median (IQR)

Received any trauma surgery

Received any general surgery procedure

Received any cardiothoracic surgery procedure

Received any neurosurgery procedure

Received any orthopedic surgery procedure

If received surgery, no. of trauma surgeries, mean (SD)

Ventilator duration

$1 \mathrm{~d}$

$2+d$

$1106(5.8)$

Not ventilated

$17547(92.2)$

If ventilated, no. of days, median (IQR)

Length of stay at lead trauma hospital, median (IQR)

Length of episode of care

$3(1-10)$

$8(4-17)$

$11(6-23)$

Disposition

Home

$9038(47.5)$

Home with support

$2163(11.4)$

Another acute care facility

$3214(16.9)$

General rehabilitation facility

$1724(9.1)$

Chronic care facility

Nursing home

$404(2.1)$

Special rehabilitation facility

$1572(8.3)$

Other§

ous admission to hospital with a diagnosis of mood disorder (hazard ratio [HR] 4.3, $95 \% \mathrm{Cl} 2.1$ to 8.8 ) and self-inflicted injury (HR 7.8, 95\% Cl 3.9 to 15.4) (Figure 3). The results were the same when we included only the patients with 5 complete years of follow-up (Supplementary Table 4 [Appendix 7, available at www.cmaj.ca/ lookup/suppl/doi:10.1503/cmaj.180368/-/ DC1]).

\section{Interpretation}

In this large, population-based study, we sought to improve understanding of the complex association between major injury and subsequent mental health outcomes. We have shown that the experience of major trauma requiring admission to a trauma centre is associated with a significant risk of admission to hospital for new or pre-existing mental health diagnoses. In addition, our results show a significant occurrence of suicide for this patient population.

Overall, it is surprising that there are relatively few data on the rate of development of new mental health diagnoses or increase in severity of pre-existing mental health diagnosis in the months to years after major injury, given previous work showing that mental well-being is the single greatest predictor of general health, ability to return to work and satisfaction with recovery among patients recovering from trauma. ${ }^{18}$

In the Canadian context, a similar population-based, self-matched cohort study examined the development of mental health conditions in patients who survived major burns. ${ }^{3}$ In this study, the overall population of patients who survived burns did not have an increase in mental health visits in the recovery period after admission; however, among the popula-

interaction by sex was significant $(Z=3.04, p=0.002)$, models stratified by sex showed similar results, albeit with less statistical significance among the female patients, likely owing to reduced statistical power in this comparatively smaller population. Patients younger than 18 years had the greatest increase in rate of postinjury hospital admissions with 1 or more mental health diagnosis (IRR $3.3,95 \% \mathrm{Cl} 1.5$ to 7.2 ). The results were very similar among the cohort with complete 5-year follow-up (Supplementary Table 3 [Appendix 6, available at www.cmaj.ca/lookup/ suppl/doi:10.1503/cmaj.180368/-/DC1]).

The suicide rate among the study cohort was 70 per 100000 patients per year. Risk factors for completing suicide were previ- tion with fewer than 1 mental health-related visit in the 3 months preceding the burn, there was a threefold increase in mental health visits during the follow-up period and rates of selfharm events increased twofold in the 3 years after a major burn.

Although we found the association between major trauma and a heightened risk of subsequent mental health-related inpatient admissions to be consistent across the entire patient population, there were several subgroups (male, low or high socioeconomic status, unintentional injury) where the association was particularly pronounced. With our study design, it is impossible to determine whether this association reflects the experience of major injury or is a consequence of the relatively lower rates of mental 
health diagnoses in these subgroups in the pre-injury phase of study (Table 3). For instance, rates of depression are generally lower in men than in women, ${ }^{19}$ and lower still in children and adolescents than adults. ${ }^{20}$ Conversely, rates of mental health-related stays in hospital in patients admitted for self-inflicted injuries are high at baseline and do not increase as substantially in the postinjury period. The experience of a major injury may put patients from these subgroups into a better position to access mental health resources and therefore cause the increased rates of mental health diagnoses that we have identified. Alternatively, these subgroups may be particularly vulnerable to impaired mental well-being during the recovery from their injury.

Among our cohort of 19338 patients, there were 62 suicides over a median follow-up of 5 years, yielding a rate of 70 per 100000 patients per year. This is considerably higher than rates described for patients with concussion (31 per 100000 patients per year), ${ }^{11}$ military personnel (14 per 100000 patients per year) ${ }^{21}$ and the overall Canadian population (11.5 per 100000 patients per year). ${ }^{8}$

\section{Limitations}

There are several limitations to our methods that are worth noting. First, our population consists entirely of patients treated at lead trauma centres in Ontario. If patients who received their inpatient care at nontrauma centres in Ontario were systematically different from those treated at trauma centres, this could limit the external generalizability of our findings. Additionally, we used an inpatient administrative database to obtain outcome information on mental health diagnoses. We made this decision as we felt that outpatient diagnostic information would be less reliable as a result of multiple sources of heterogeneity relating to types of providers, care settings, billing practices and confidence in making mental health diagnoses. As such, it is probable that we have underestimated the strength of association between major injury and subsequent mental health diagnoses, as many patients postinjury with mental health diagnoses may not require admission to hospital, and will seek outpatient care. ${ }^{2}$

A few limitations related to the exposure-crossover design ${ }^{22}$ should be mentioned. First, the exposure of interest must be acute in onset, and the development of the outcome in association with the exposure must temporally follow the exposure. The exposure in our study did have an acute onset, although the development of mental health problems may have been somewhat delayed. Second, if there are independent time trends in the outcomes (i.e., an increasing prevalence of mental health conditions in the population at large), then the association between exposure and outcome can be spurious. We have no evidence to suggest that there are temporal trends in mental health

Table 3: Composite rates of mental health diagnoses within 5 years of major injury

Composite rate per 1000 patient years

\section{Characteristic}

All patients

Sex

Female

Male

Age group, $y r$

$<18$

$18-29$

$30-49$

$50-69$

$70+$

Income quartile

Lowest

Highest

Home location

Rural

Urban

Intention of injury

Self-inflicted

Assault

Unintentional

Any trauma surgery procedures*
5 years before injury

$5.7(4.5-7.2)$

$6.9(5.2-9.1)$

$4.7(3.8-5.9)$

$0.9(0.4-2)$

$5.5(4.2-7.3)$

$12.5(10.1-15.5)$

$14.6(11.7-18.2)$

$6.4(5-8.3)$

$7.5(5.8-9.6)$

$4.7(3.4-6.5)$

$4.9(3.6-6.7)$

$6.6(5.4-8.1)$

16 (11.6-21.9)

$4.9(3.4-7.1)$

$2.3(1.9-2.9)$

$5.3(4-7)$
5 years after injury

$8.1(6.9-9.5)$

$8.3(6.8-10.2)$

$7.9(6.8-9.2)$

$3(2.1-4.3)$

$6.6(5.3-8.1)$

$14.6(12.2-17.4)$

$15.5(13-18.6)$

$7.8(6.2-9.8)$

$11.2(9.3-13.5)$

$7.3(5.7-9.4)$

$7.7(6.2-9.7)$

$8.5(7.4-9.8)$

$18.8(14.7-24)$

$6.2(4.8-8.1)$

$4.6(4-5.2)$

$7.4(6.1-8.9)$

${ }^{*}$ Categories $=$ general surgery, thoracic surgery billing codes, etc. 
diagnoses over the time periods of our study. Lastly, the assumption of the study design is that the exposure cannot prevent the outcome from occurring, yet it is possible that trauma may preclude some individuals from seeking mental health assistance or diagnoses because of competing health care problems or disability. However, in this case the associations we observed in our study would actually be a conservative estimate of the association between trauma and mental health problems.

Another limitation of using administrative data relates to substance abuse diagnoses. Although the exposure-crossover design controls for an individual's measured baseline conditions (like substance abuse, Table 1), it is possible that if these diagnoses were not comprehensively captured in the pre-injury period of study (i.e., if a patient had a substance abuse problem that was not severe enough to lead to an inpatient admission), compared with the postinjury phase of care, then an apparent increase in mental health diagnoses may occur that is not a result of the experience of injury itself, but rather from being exposed to health care providers who then have the opportunity to make the diagnosis of substance abuse.
We excluded several patient groups in an effort to remain focused on the primary question of the effect of a single major and unanticipated major injury on mental health outcomes. We excluded patients with more than 1 entry in the Ontario Trauma Registry, for instance, as these patients presumably suffered more than 1 major injury during the study period and we felt they were at substantially different risk of developing new mental health diagnoses than patients with only 1 admission for major injury. As there were only 391 patients (Figure 1) with more than 1 Ontario Trauma Registry entry, we believe the effects of selection bias on the study's conclusions are minimal.

We intentionally included patients with self-inflicted injuries in sample so that we would have a more robust understanding of the mental health course of this particularly at-risk patient group. Doing so, we acknowledge that there is possibly some residual confounding related to these patients' pre-injury mental health status that may artificially increase the strength of the association between major injury and a new mental health diagnosis.

It is also worth noting that at first glance, our data could be perceived as dated. There are a few reasons for our using this time

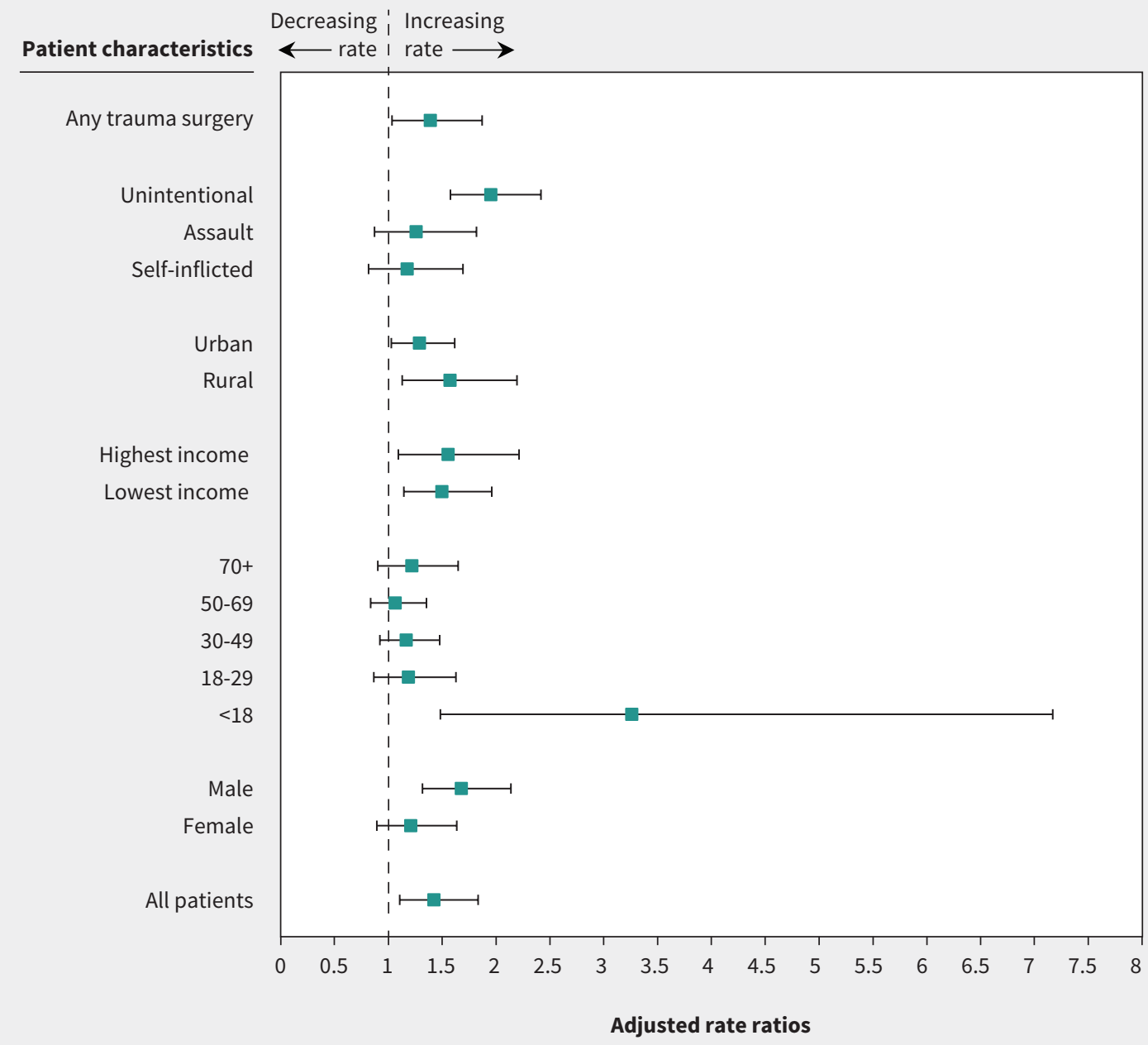

Figure 2: Patient characteristics associated with pre- v. post-inpatient mental health diagnoses within 5 years of major trauma (adjusted rate ratios [95\% confidence intervals]; $n=19$ 338). Each variable was tested with the others shown (i.e., age, gender, socioeconomic status, residence, nature of injury, requirement for surgery). 
Table 4: Pre- and postinjury frequency of patients with at least 1 admission with an

associated mental health diagnosis by diagnosis subtype

\begin{tabular}{|c|c|c|c|}
\hline Diagnosis & $\begin{array}{l}\text { No. of patients } \\
\text { pre-injury (\%) } \\
n=19338\end{array}$ & $\begin{array}{c}\text { No. of patients } \\
\text { postinjury (\%) } \\
n=19338\end{array}$ & $p$ value \\
\hline Alcohol abuse & $412(2.1)$ & $465(2.4)$ & $<0.001$ \\
\hline Drug abuse & $228(1.2)$ & $247(1.3)$ & $<0.001$ \\
\hline Major depressive disorders & $241(1.3)$ & $373(1.9)$ & $<0.001$ \\
\hline Bipolar disorders & $91(0.5)$ & $66(0.3)$ & $<0.001$ \\
\hline Other mood disorder* & $40(0.2)$ & $16(0.08)$ & 0.96 \\
\hline $\begin{array}{l}\text { Acute stress disorder, PTSD and } \\
\text { other adjustment disorders }\end{array}$ & $54(0.3)$ & $77(0.4)$ & $<0.001$ \\
\hline Anxiety disorders $\dagger$ & $103(0.5)$ & $120(0.6)$ & $<0.001$ \\
\hline $\begin{array}{l}\text { Other nonpsychotic mental } \\
\text { disorders } \ddagger\end{array}$ & $11(0.06)$ & $<6(<0.03)$ & 0.99 \\
\hline
\end{tabular}

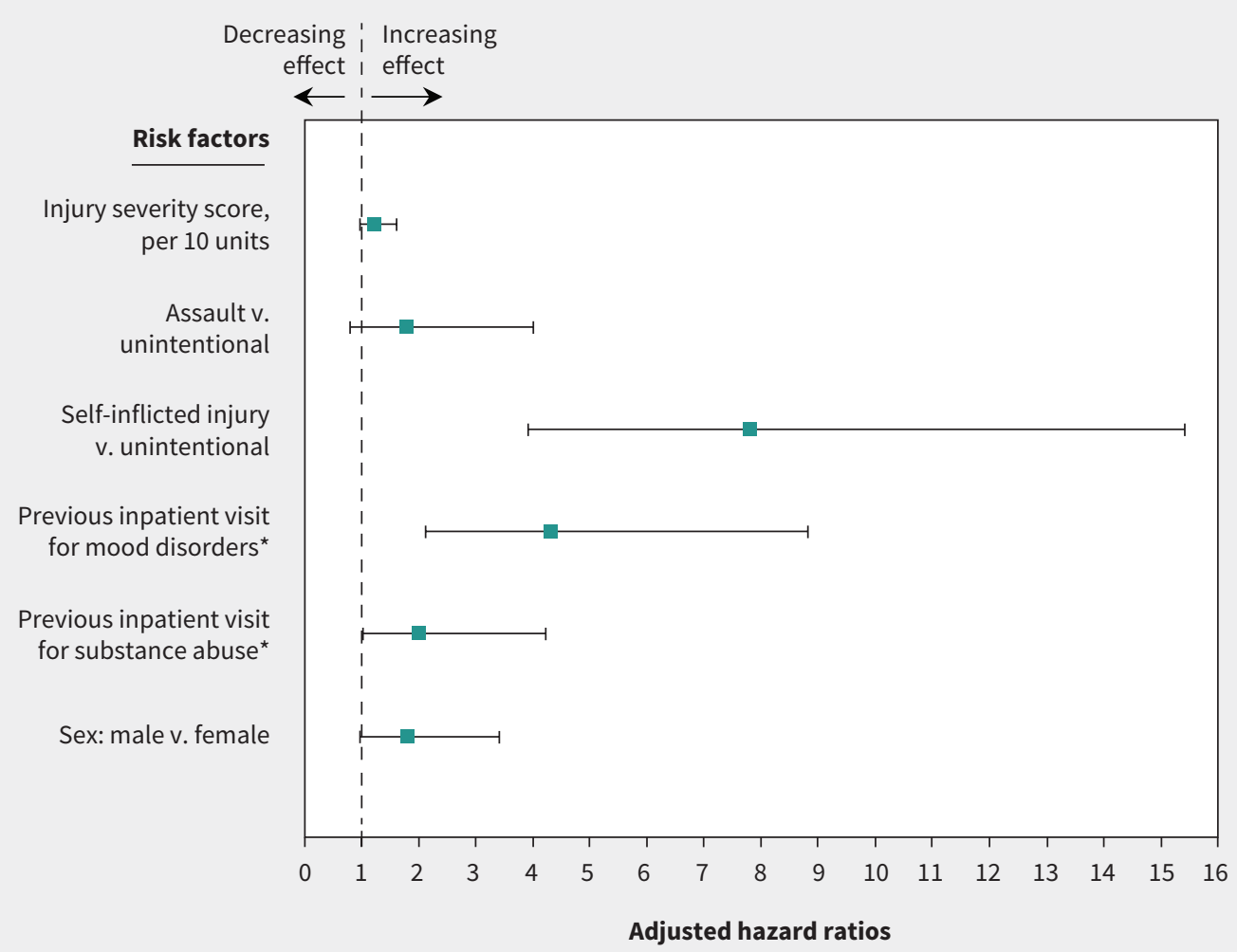

Figure 3: Risk factors associated with completing suicide within 5 years of major injury (adjusted hazard ratios [with 95\% confidence intervals] for completing suicide; $n=19$ 338). Adjusted variables were age, gender, socioeconomic status, nature of injury, requirement for surgery, and all risk factors shown. ${ }^{*}$ Within 5 years before injury.

period. First, the accrual window of 2005-2010 was necessary, as we wanted to have a 5-year follow-up window (2010-2015) for mental health outcomes in all patients. Using a more recent accrual period would have necessitated shortening the follow-up period, and we thought that was a less desirable alternative, as important outcomes (including suicide) might have been missed. At the time of data analysis, we did use the most recently available data from the Ontario Trauma Registry (2015), and our 
population does also include 3 additional years of more recent data (2012-2015) than another recent Canadian study that examined the association between concussions and suicide. ${ }^{11}$

Our study was not designed to explore in detail the association between injury and mental illness among the various different subgroups of patients with major trauma. However, we found a particularly strong association between such injury and inpatient admissions for mental health diagnoses in the pediatric (younger than 18 years) population; this group should be an area of particular focus in future research efforts.

\section{Conclusion}

Patients who suffer major traumatic injury are at significant risk of increased admissions to hospital with mental health diagnoses in the years after their injury and of having high suicide rates during this period. All patients appear to be at risk of completing suicide, with the highest-risk patients being those with a history of preexisting mood disorder and those recovering from a self-inflicted injury. Mental health resources should be offered to all survivors of major trauma, and particularly intense supports directed to the highest-risk patients.

\section{References}

1. Bryant RA, O'Donnell ML, Creamer M, et al. The psychiatric sequelae of traumatic injury. Am J Psychiatry 2010;167:312-20.

2. Bryant RA, O'Donnell ML, Forbes D, et al. The course of suicide risk following traumatic injury. J Clin Psychiatry 2016;77:648-53.

3. Mason SA, Nathens AB, Byrne JP, et al. Association between burn injury and mental illness among burn survivors: a population-based, self-matched, longitudinal cohort study. J Am Coll Surg 2017;225:516-24.

4. Nathens $A B$. Life after discharge following major injury: expanding our notion of quality in trauma care. Ann Surg 2016;263:633-5.

5. Castillo RC, Wegener ST, Heins SE, et al.; LEAP Study Group. Longitudinal relationships between anxiety, depression, and pain: results from a two-year cohort study of lower extremity trauma patients. Pain 2013;154:2860-6.

6. Clous EA, Beerthuizen KC, Ponsen KJ, et al. Trauma and psychiatric disorders: A systematic review. J Trauma Acute Care Surg 2017;82:794-801.
7. March J, Sareen J, Gawaziuk JP, et al. Increased suicidal activity following major trauma: a population-based study. J Trauma Acute Care Surg 2014;76:180-4.

8. Navaneelan T. Health at a glance - Suicide rates: an overview. Ottawa: Statistics Canada; (modified 2017 June 16). Available: www.statcan.gc.ca/pub/82-624-x /2012001/article/11696-eng.htm (accessed 2018 Feb. 5).

9. Wiseman T, Foster K, Curtis K. Mental health following traumatic physical injury: an integrative literature review. Injury 2013;44:1383-90.

10. Zatzick D, Jurkovich GJ, Rivara FP, et al. A national US study of posttraumatic stress disorder, depression, and work and functional outcomes after hospitalization for traumatic injury. Ann Surg 2008;248:429-37.

11. Fralick M, Thiruchelvam D, Tien HC, et al. Risk of suicide after a concussion. CMAJ 2016;188:497-504.

12. Redelmeier DA. The exposure-crossover design is a new method for studying sustained changes in recurrent events. J Clin Epidemiol 2013;66:955-63.

13. Ontario [Province] and Canada [Country] (table). Census profile. 2016 Census. Cat no 98-316-X2016001. Ottawa: Statistics Canada; 2017 Nov. 29 (modified 2018 Apr. 24). Available: www12.statcan.gc.ca/census-recensement/2016/ dp-pd/prof/details/page.cfm?Lang=E\&Geo1=PR\&Code1=35\&Geo2=PR\&Code2 $=01 \&$ Data $=$ Count $\&$ SearchText=ontario $\&$ SearchType=Begins $\&$ SearchPR=01\&B1 $=$ All\&TABID $=1$ (accessed 2018 Feb. 5).

14. Austin PC, Stanbrook MB, Anderson GM, et al. Comparative ability of comorbidity classification methods for administrative data to predict outcomes in patients with chronic obstructive pulmonary disease. Ann Epidemiol 2012;22:881-7.

15. Brewer N, Borman B, Sarfati D, et al. Does comorbidity explain the ethnic inequalities in cervical cancer survival in New Zealand? A retrospective cohort study. BMC Cancer 2011;11:132.

16. Elixhauser A, Steiner C, Harris DR, et al. Comorbidity measures for use with administrative data. Med Care 1998;36:8-27.

17. Kralj B. Measuring "rurality" for purposes of health-care planning: an empirical measure for Ontario. Ont Med Rev 2000;67:33-52.

18. Michaels AJ, Michaels CE, Smith JS, et al. Outcome from injury: general health, work status, and satisfaction 12 months after trauma. J Trauma 2000;48:841-8, discussion 848-50.

19. Pedersen CB, Mors O, Bertelsen A, et al. A comprehensive nationwide study of the incidence rate and lifetime risk for treated mental disorders. JAMA Psychiatry 2014;71:573-81.

20. Perou R, Bitsko RH, Blumberg SJ, et al.; Centers for Disease Control and Prevention (CDC). Mental health surveillance among children - United States, 20052011. MMWR Suppl 2013;62:1-35.

21. Bogaert L, Whitehead J, Wiens M. al. Suicide in the Canadian Forces 1995 to 2012. Ottawa: Department of National Defence; 2013.

22. Maclure M, Mittleman MA. Should we use a case-crossover design? Annu Rev Public Health 2000;21:193-221.
Competing interests: Dallas Seitz reports grants from Roche and Avanir Pharmaceuticals, outside the submitted work. No other competing interests were declared.

This article has been peer reviewed.

Affiliations: Department of Emergency Medicine (Evans) and Psychiatry (Seitz), and ICES (DeWit, Hall, Seitz), Queen's University, Kingston, Ont.; Department of Surgery (Mason, Nathens), University of Toronto, Toronto, Ont.

Contributors: Christopher Evans conceived the study. Yvonne DeWitt performed the data analyses. All of the authors contributed to the design of the study, drafted the manuscript, revised it critically for important intellectual content, gave final approval of the version to be published and agreed to be accountable for all aspects of the work.

Funding: This study was funded by a grant provided by the Clinical Teacher's Association of Queen's University. Additionally, this study was supported by ICES, which is funded by an annual grant from the Ontario Ministry of Health and Long-Term Care (MOHLTC).
Data sharing: All data can be shared with researchers subject to ICES Queen's policies and approval.

Acknowledgements: The authors wish to thank Dr. Zachary Warren for editing an early version of the manuscript. Individuals who wish to access the study protocol, raw data, programming code, etc., should contact the corresponding author.

Disclaimer: Parts of this material are based on data or information compiled and provided by the Canadian Institute for Health Information (CIHI). However, the analyses, conclusions, opinions and statements expressed in the material are those of the authors, and not necessarily those of $\mathrm{CIHI}$. In addition, this study was supported by ICES, which is funded by an annual grant from MOHLTC. The opinions, results and conclusions reported in this paper are those of the authors and are independent from the funding sources. No endorsement by ICES or the Ontario MOHLTC is intended or should be inferred.

Accepted: Sept. 17, 2018

Correspondence to: Christopher Evans, c.evans@queensu.ca 